\title{
Tree rings reveal two strong solar proton events in 7176 and 5259 BCE
}

Nicolas Brehm ( $\square$ nbrehm@ethz.ch )

ETH Zürich

\section{Marcus Christl}

ETH Zürich https://orcid.org/0000-0002-3131-6652

\section{Florian Adolphi}

Alfred Wegener Institute for Polar and Marine Research https://orcid.org/0000-0003-0014-8753

\section{Raimund Muscheler}

Lund University https://orcid.org/0000-0003-2772-3631

\section{Hans-Arno Synal}

ETH Zürich

\section{Florian Mekhaldi}

Lund University https://orcid.org/0000-0001-8323-2955

\section{Chiara Paleari}

Lund University https://orcid.org/0000-0002-0007-5155

\section{Hanns-Hubert Leuschner}

4Albrecht von Haller Institute for Plant Sciences

\section{Alexandra Bayliss}

Historic England https://orcid.org/0000-0003-2782-1979

\section{Kurt Nicolussi}

University of Innsbruck https://orcid.org/0000-0002-1737-4119

\section{Thomas Pichler}

Universität Innsbruck

\section{Christian Schlüchter}

University of Bern

\section{Charlotte Pearson}

University of Arizona

\section{Matthew Salzer}

University of Arizona https://orcid.org/0000-0001-5353-7459

\section{Patrick Fonti}

Swiss Federal Institute for Forest, Snow and Landscape Research https://orcid.org/0000-0002-70703292

\section{Daniel Nievergelt}

Swiss Federal Institute for Forest, Snow and Landscape Research 


\section{Rashit Hantemirov}

Institute of Plant and Animal Ecology, Ural Branch of the Russian Academy of Sciences

\section{David Brown}

The Queen's University

\section{llya Usoskin}

University of Oulu https://orcid.org/0000-0001-8227-9081

\section{Lukas Wacker}

Swiss Federal Institute of Technology (ETH) https://orcid.org/0000-0002-8215-2678

\section{Article}

Keywords: solar energetic particles, 14C concentrations, extreme solar events

Posted Date: August 10th, 2021

DOI: https://doi.org/10.21203/rs.3.rs-753272/v1

License: (c) (1) This work is licensed under a Creative Commons Attribution 4.0 International License. Read Full License

Version of Record: A version of this preprint was published at Nature Communications on March 7th, 2022. See the published version at https://doi.org/10.1038/s41467-022-28804-9. 


\section{Tree-rings reveal two strong solar proton events in 7176 and 5259 $\mathrm{BCE}$}

Nicolas Brehm ${ }^{1}$, Marcus Christl ${ }^{1}$, Florian Adolphi ${ }^{2}$, Raimund Muscheler ${ }^{3}$, Hans-Arno Synal ${ }^{1}$, Florian Mekhaldi ${ }^{2}$, Chiara Paleari ${ }^{2}$, Hanns-Hubert Leuschner ${ }^{4}$, Alex Bayliss ${ }^{5}$, Kurt Nicolussi ${ }^{6}$, Thomas Pichler ${ }^{6}$, Christian Schlüchter ${ }^{7}$, Charlotte L. Pearson ${ }^{8}$, Matthew W. Salzer ${ }^{8}$, Patrick Fonti ${ }^{9}$, Daniel Nievergelt ${ }^{9}$, Rashit Hantemirov ${ }^{10,11}$, David M. Brown ${ }^{12}$, Ilya Usoskin ${ }^{13}$, Lukas Wacker ${ }^{1}$

${ }^{1}$ Laboratory of Ion Beam Physics, ETHZ, Otto-Stern Weg 5 HPK, 8093 Zurich, Switzerland

${ }^{2}$ Alfred Wegener Institute for Polar and Marine Research, 27568 Bremerhaven, Germany

${ }^{3}$ Department of Geology - Quaternary Sciences, Lund University, 22362, Lund, Sweden

${ }^{4}$ Albrecht von Haller Institute for Plant Sciences, Department of Palynology and Climate Dynamics, Georg-August-University, Wilhelm-Weber-Str. 2a, 37073 Göttingen, Germany

${ }^{5}$ Historic England, Cannon Bridge House, 25 Dowgate Hill, London, EC4R 2YA, UK

${ }^{6}$ Department of Geography, Universität Innsbruck, Innrain 52, 6020 Innsbruck, Austria

${ }^{7}$ Institute of Geological Sciences, University of Bern, Baltzerstrasse 1+3, 3012 Bern, Switzerland

${ }^{8}$ University of Arizona, Bryant Bannister Tree-Ring Building, 1215 E. Lowell Street, Tucson, AZ 857210045, USA

${ }^{9}$ Eidgenössische Forschungsanstalt WSL, Zürcherstrasse 111, 8903 Birmensdorf, Switzerland

${ }^{10}$ Laboratory of Dendrochronology, Institute of Plant and Animal Ecology, Ural Branch of Russian Academy of Sciences, 8 Marta Street, 202, Ekaterinburg 620144, Russia

${ }^{11}$ Laboratory of Natural Science Methods in Humanities, Ural Federal University, 19 Mira Street, Ekaterinburg 620002, Russia

${ }^{12}$ School of Natural and Built Environment, The Queen's University, Belfast, BT7 1NN, UK

${ }^{13}$ Sodankylä Geophysical Observatory and Space Physics and Astronomy Research Unit, University of Oulu, Oulu, FIN-90014, Finland

\section{Abstract}

The Sun sporadically produces eruptive events leading to intense fluxes of solar energetic particles (SEPs) that dramatically disrupt the near-Earth radiation environment. Such events are directly studied for the last decades but little is known about the occurrence and magnitude of rare, extreme SEP events. Presently, a few events that produced measurable signals in cosmogenic radionuclides such as ${ }^{14} \mathrm{C},{ }^{10} \mathrm{Be}$ and ${ }^{36} \mathrm{Cl}$ have been found. Analyzing annual ${ }^{14} \mathrm{C}$ concentrations in tree-rings from Switzerland, Germany, Ireland, Russia, and the USA we discovered two spikes in atmospheric ${ }^{14} \mathrm{C}$ corresponding to 7176 and $5259 \mathrm{BCE}$. The $\sim 2 \%$ increases of atmospheric ${ }^{14} \mathrm{C}$ recorded for both events exceed all previously known ${ }^{14} \mathrm{C}$ peaks but after correction for the geomagnetic field, they are comparable to the largest event of this type discovered so far at $775 \mathrm{CE}$. These strong events serve as accurate time markers for the synchronization with floating tree-ring and ice core records and provide critical information on the previous occurrence of extreme solar events which threaten modern infrastructure.

\section{Introduction}

The Sun sporadically produces eruptive events, such as flares and coronal mass ejection, that can lead to highly intense fluxes of solar energetic particles (SEPs), which escape into the interplanetary space and possibly hit Earth ${ }^{1}$. When reaching the Earth, SEPs can have a dramatic impact on modern communication, navigation and power systems, satellite life expectancy, the health of astronauts, and aircraft operations ${ }^{2,3}$. The famous Carrington event was one of the strongest known solar storms 
that hit the Earth in September 1859 CE, leading to a widespread failure of the telegraph system and observable auroras all over the world ${ }^{3,4}$. If this, or an even larger event, occurred today the impact on global society and economy would be catastrophic ${ }^{3,5}$.

The first instrumental observations of SEPs were conducted in the $1940 \mathrm{~s}^{6}$. Since then their physical origin, frequency of occurrence, amplitude, and energy distribution have been studied using groundbased and space-borne data ${ }^{7}$. The strongest measured SEP event (called ground-level-enhancement GLE \#5) took place on 23-Feb-1956 (a list of directly measured events is available at the International GLE database (https://gle.oulu.fi)). However, little is known about extreme SEP events whose very existence was been unknown several years ago ${ }^{8}$. Even though observational advances such as a worldwide network of neutron monitors (established in 1951/1957/1964) made it possible to characterize the Suns' eruptive behavior ${ }^{9}$, the temporal coverage of the observational record is not long enough to assess the frequency of extremely rare but highly energetic SEP events. Statistics of sun-like stars suggest that superflares are extremely rare ${ }^{10,11}$.

Understanding and ultimately predicting extreme solar events will not only help in mitigating their harmful consequences on modern life and communication systems, but will also help understanding the complex magneto-hydrodynamic behavior of the Sun. In this context, cosmogenic radionuclides provide a powerful tool for reconstructing past solar activity and SEP events ${ }^{12-15}$.

Cosmogenic radionuclides such as ${ }^{10} \mathrm{Be},{ }^{14} \mathrm{C}$ and ${ }^{36} \mathrm{Cl}$ are mainly produced by galactic cosmic rays (GCRs) originating from outside our solar system, hitting the Earth's atmosphere. The flux of GCRs on Earth is modulated (shielded) by the geomagnetic field and the solar magnetic field carried by the solar wind ${ }^{16}$. As a consequence, enhanced magnetic fields (solar/heliospheric or geomagnetic) reduce cosmogenic nuclide production by GCRs on Earth and vice versa. When hitting the Earth, strong SEPs may cause an additional, short-term increase in cosmogenic nuclide production. Natural archives, such as dendrochronologically dated tree-rings $\left({ }^{14} \mathrm{C}\right)$ or polar ice cores $\left({ }^{10} \mathrm{Be},{ }^{36} \mathrm{Cl}\right)$, are known to provide precise and temporally accurate records of past cosmogenic radionuclide production ${ }^{12,17,18}$ giving us a unique opportunity to identify and study the characteristics of strong SEP events over the past thousands of years.

So far, three strong SEP events that led to an abrupt increase of about $1 \%$ or more in atmospheric ${ }^{14} \mathrm{C}$ concentrations within less than two years have been unambiguously detected over the past 3000 years in tree-rings and confirmed with other cosmogenic radionuclides $\left({ }^{10} \mathrm{Be},{ }^{36} \mathrm{Cl}\right)$ in ice cores, in the years $993 \mathrm{CE}, 775 \mathrm{CE}$ and $660 \mathrm{BCE}^{13,14,19,20}$. More, weaker, yet unconfirmed SEP events have been found in the radionuclide records ${ }^{17,21-23}$. They are currently considered candidate events either because there is insufficient data coverage and precision to clearly distinguish them from normal solar modulation or because they have not yet been confirmed ${ }^{24}$. The above mentioned Carrington Event did not lead to a detectable increase in cosmogenic radionuclides ${ }^{17,25,26}$ implying that associated SEPs either missed the Earth or did not have sufficient energy.

The longest absolutely dated composite tree-ring record spans the last 12,460 years ${ }^{27}$. At present, high-precision, annual ${ }^{14} \mathrm{C}$ measurements from tree-rings, which are required for the sensitive detection of strong SEP events, only cover about 2030 years $^{28}$. Therefore, our ability to study strong SEP events is limited and theoretical estimations on their frequency ${ }^{9}$ and energy spectra ${ }^{20,29}$ remain highly uncertain. The extension of the time period covered with annually resolved ${ }^{14} \mathrm{C}$ measurements in tree-rings will provide statistically robust estimates on the magnitude and frequency of strong SEP events.

Currently, the search for strong SEP events mainly relies on existing cosmogenic nuclide records with lower (5- or 10-years) temporal resolution. The motivation to investigate the annually resolved ${ }^{14} \mathrm{C}$ signal in tree-rings between 7150 BCE and 7200 BCE came from lower resolution, synchronized ${ }^{30,31}$ 
${ }^{10} \mathrm{Be}$ and ${ }^{36} \mathrm{Cl}$ data in ice cores ${ }^{32-34}$ and from decadal ${ }^{14} \mathrm{C}$ data (IntCal20) ${ }^{28}$. Another event in $5259 \mathrm{BCE}$, was discovered while investigating unexpected difficulties in producing stable Bayesian chronological models for archaeological sites and ceramic sequences dating to the period centering on the 53rd century $\mathrm{BCE}^{35-37}$. With hindsight, this event could not have been detected by the statistical analysis of cosmogenic nuclides from the lower resolution ice core data ${ }^{38}$.

Here we present two previously unknown ${ }^{14} \mathrm{C}$ production events recorded in two (7176 BCE) and four (5259 BCE) independent, absolutely dated tree-ring chronologies. The magnitudes of the events are assessed by calculating the additional ${ }^{14} \mathrm{C}$ production using a global carbon cycle box model. They are compared to other known ${ }^{14} \mathrm{C}$ events by normalizing their magnitudes to modern geomagnetic shielding. Furthermore, the $7176 \mathrm{BCE}$ event is used as a unique time marker to place a floating (i.e. not absolutely dated) portion of the Bristlecone Pine tree-ring chronology (USA) within 1-2 years on its absolutely dated part.

\section{Results}

Atmospheric ${ }^{14} \mathrm{C}$ concentrations measured in several independently built tree-ring chronologies increased by nearly $2 \%$ within two years in 7176 BCE and 5259 BCE (Figure 1, Table 1,Supplementary Fig 1) thereby exceeding the rise in ${ }^{14} \mathrm{C}$ concentration of the largest known event in $775 \mathrm{CE}^{14}$. For the $7176 \mathrm{BCE}$ event (Figure 1a) an average increase of $(19.5 \pm 0.6) \%$ in ${ }^{14} \mathrm{C}$ concentrations was observed in the two existing absolutely dated tree-ring chronologies from central Europe covering that time range, the German oak and the Eastern Alpine Conifer ${ }^{39,40}$ chronologies. The 7176 BCE event was also found in a currently floating portion of the Bristlecone Pine chronology from the USA (supplementary information S1).

The 5259 BCE event (Figure 1b) was found in four absolutely dated tree-ring chronologies from the Alps, Ireland, Russia and the USA showing an average increase in atmospheric ${ }^{14} \mathrm{C}$ concentrations of $(19.1 \pm 0.6) \%$. We note that the USA Bristlecone record shows a potential increase already in 5260 BCE. This ambiguous result might be caused by the narrow tree-ring widths $(<0.5 \mathrm{~mm})$ hampering a distinct separation of adjacent rings.

Total and excess ${ }^{14} \mathrm{C}$ productions from the SEP event were calculated using a global carbon cycle model $^{17}$ (Methods). The excess production (and related uncertainty) was calculated using a Monte Carlo approach by fitting offset and amplitude of a Gaussian-shaped production spike to the data (Figure 2, Methods). For each of the 1000 different Monte Carlo data realizations the amount of additional ${ }^{14} \mathrm{C}$ produced was extracted. The average amount of excess ${ }^{14} \mathrm{C}$ produced during the two events was (29.2 \pm 0.9$) \mathrm{kg}$ for the $5259 \mathrm{BCE}$ event and (28.7 \pm 0.9$) \mathrm{kg}$ for the $7176 \mathrm{BCE}$ event (Table1). This is more than (7176 BCE) or comparable to (5259 BCE) the amount of ${ }^{14} \mathrm{C}$ produced by the strongest ${ }^{14} \mathrm{C}$ event detected so far $\left(775 \mathrm{CE},(26.2 \pm 1.0) \mathrm{kg}\right.$ excess $\left.{ }^{14} \mathrm{C}\right)$. In both cases, a modeled duration of $0.3 \mathrm{yr}, 2$-sigma of the Gaussian, was used to fit the measured ${ }^{14} \mathrm{C}$ increase. This is significantly less than the tree-ring resolution of one year.

Excess ${ }^{14} \mathrm{C}$ production of all known events (Supplementary Fig 3) was (re-)calculated using the above described procedure (Figure 2a). When comparing different events, it is, however, important to note that the same event (in terms of the proton flux and energy distribution) can lead to different excess productions of cosmogenic radionuclides depending on the strength of the Earth's geomagnetic field at the time of the event. A weak geomagnetic field would result in higher excess production of cosmogenic radionuclides by the SEP event and vice versa. We therefore recalculated the excess ${ }^{14} \mathrm{C}$ production by normalizing all events relative to the modern geomagnetic dipole moment of $7.8 \cdot 10^{22}$ $\mathrm{Am}^{2}$ using two different geomagnetic field records ${ }^{41,42}$ (see Methods/ Supplementary Fig 4/5)(Figure 
3). The resulting normalized excess ${ }^{14} \mathrm{C}$ productions for the $7176 \mathrm{BCE}$ event are not significantly different from the original value (Table 1). The 5259 BCE event occurred during the period of weaker magnetic field strength and, thus, referring to modern geomagnetic shielding the excess ${ }^{14} \mathrm{C}$ production would be slightly lower. The normalization procedure also significantly changes the excess ${ }^{14} \mathrm{C}$ production of the other known events. For the $775 \mathrm{CE}$ event, the two geomagnetic field reconstructions give different results, while the Knudsen ${ }^{42}$ reconstruction leads to a $20 \%$ increase of excess ${ }^{14} \mathrm{C}$, using the Panovska ${ }^{41}$ reconstruction increases it by only $10 \%$. When comparing the events after normalization we observe that the $7176 \mathrm{BCE}$ and the 5259 BCE events are of similar, but slightly weaker magnitude than the $775 \mathrm{CE}$ event. In any case, they are significantly stronger than both 660 BCE and 993 CE events.

\section{Discussion}

The two newly-identified events are unambiguously assigned to the years 5259 BCE and 7176 BCE in several independent and absolutely dated tree-ring chronologies. The fact that the events are accurately dated to one year makes them (and all other ${ }^{14} \mathrm{C}$ events) excellent time markers for the synchronization of chronologies. For example, an older floating portion of the USA Bristlecone chronology could not be comprehensively connected to its master chronology using tree-ring dating techniques, due to a very short (not statistically verifiable) period of overlap between the records. Instead, this chronology was assigned possible calendar dates based upon a tentative dendrochronological match within a broader time window suggested by conventional radiocarbon dating ${ }^{43}$ (see SI for full details). The results of this analysis clearly showed the 7176 BCE event within a one-year accuracy of the revised dating placement. This allowed us to place this sequence on an absolute timescale for the first time. Considering the ambiguous result of the 5259 BCE event in the Bristlecone Pine chronology we can now place the portion of the full sequence beyond 6827 BCE within \pm 1 year. Additional measurements of the very narrow, highly resinous tree-rings of less than $0.5 \mathrm{~mm}$ width, that could not be separated perfectly (see Suppl. Information) will potentially allow for an absolute positioning of this extension of the Bristlecone chronology in the future, which would complete the annually resolved record from the Methuselah Walk chronology for 10,399 years.

Polar ice cores, which are regarded as extremely valuable climate archives, can only be dated with a precision of about 10 years within the Holocene ${ }^{30}$ and even less in the transition to the glacial period ${ }^{44}$. The absolutely dated ${ }^{14} \mathrm{C}$ events in tree-rings can now be used to synchronize the ice core chronologies via cosmogenic ${ }^{10} \mathrm{Be}$ and ${ }^{36} \mathrm{Cl}$ resulting in a precision of about $1-2$ years limited by several factors such as weather noise, sampling, and radionuclide transfer times to the ice core (Paleari et al. 2021, submitted). As a result, chronologies that so far were synchronized with absolutely dated tree-ring records using the low resolution structure of existing ${ }^{14} \mathrm{C}$ or ${ }^{10} \mathrm{Be}$ records $\mathrm{s}^{30}$ can now be placed within 1-2 years or about 10 times more precisely around these events using the abrupt change in radionuclide concentrations caused by SEP events.

The increasing number of discovered strong SEP events hitting Earth over the past 10,000 years indicates that they cannot be considered as extremely rare. So far, only $16.5 \%$ ( $2030 \mathrm{yr}$ ) of the past 12,400 years have been analyzed for ${ }^{14} \mathrm{C}$ at the annual or biennial resolution required to detect SEP events, resulting in five unambiguously detected strong SEP events (Figure 4). This might lead to the conclusion that strong SEP events hit Earth once every about 400 years on average. This simple statistic, however, is likely biased by the fact that some studied time periods were not randomly selected for annual analysis, but rather were targeted based on indications from lower-resolution cosmogenic datasets or archaeological evidence that the present multi-annual ${ }^{14} \mathrm{C}$ record might contain more structure than previously visible. We nevertheless can expect more events to be discovered as additional annually resolved data becomes available, leading to better estimates of the frequency and magnitude of SEP events. However, it is unlikely that the event much stronger than 
that of $775 \mathrm{CE}$ can be found over the Holocene ${ }^{8}$. Ranking among the three largest short-term ${ }^{14} \mathrm{C}$ production events, the impact of the newly discovered events would have been catastrophic for aircraft, satellites, modern telecommunication and computer systems $\mathrm{s}^{45-47}$, if they occurred today. This greatly improves the existing estimates based on only a few extreme events known until recently. In particular, a discrepancy exists between extreme-event occurrence rates estimated from the terrestrial proxy data ${ }^{9}$ and those assessed from the statistic of superflares on sun-like stars ${ }^{10,11}$. The new results imply a higher occurrence rate of extreme events than thought before. The statistical constraints provided by the new data will help to test different approaches in solar/stellar physics describing the occurrence and magnitude of extreme events in sun-like stars. 
Table 1: The modeled atmospheric ${ }^{14} \mathrm{C}$ increases, produced ${ }^{14} \mathrm{C}$ and normalized ${ }^{14} \mathrm{C}$ produced at the morden earth magnetic field is given for new and known events.

\begin{tabular}{|c|c|c|c|c|c|c|}
\hline & $\begin{array}{l}\text { Simulated } \\
\Delta^{14} C \\
\text { increase } \\
(\% \circ)\end{array}$ & $\begin{array}{l}\text { Additional } \\
{ }^{14} \mathrm{C} \\
\text { produced } \\
(\mathrm{kg})\end{array}$ & $\begin{array}{l}\text { Geomagnetic } \\
\text { field strength } \\
\left(10^{22} \mathrm{Am}^{2}\right) \\
\text { Knudsen }\end{array}$ & $\begin{array}{l}\text { Geomagnetic } \\
\text { field } \\
\text { strength } \\
\left(10^{22} \mathrm{Am}^{2}\right) \\
\text { Panovska }\end{array}$ & $\begin{array}{l}\text { Normalized } \\
\text { additional } \\
{ }^{14} \mathrm{C} \\
\text { produced } \\
(\mathrm{kg}) \\
(\mathrm{M}= \\
7.8 \cdot 10^{22} \mathrm{Am} \\
\left.{ }^{2}\right) \\
\text { Knudsen }\end{array}$ & $\begin{array}{l}\text { Normalized } \\
\text { additional } \\
{ }^{14} \mathrm{C} \\
\text { produced } \\
(\mathrm{kg}) \\
(\mathrm{M}= \\
7.8 \cdot 10^{22} \mathrm{Am} \\
\left.{ }^{2}\right) \\
\text { Panovska }\end{array}$ \\
\hline $\begin{array}{l}7176 \text { BCE } \\
\text { (This } \\
\text { Study) }\end{array}$ & $19.5 \pm 0.6$ & $28.7 \pm 0.9$ & $8.7 \pm 1.7$ & $7.5 \pm 0.4$ & $30.1 \pm 3.6$ & $28.0 \pm 1.2$ \\
\hline $\begin{array}{l}5410 \\
\text { BCE }^{23}\end{array}$ & $5.6 \pm 0.8$ & $9.0 \pm 1.1$ & $7.2 \pm 0.6$ & $7.3 \pm 0.4$ & $8.6 \pm 1.1$ & $8.6 \pm 1.1$ \\
\hline $\begin{array}{l}5259 \text { BCE } \\
\text { (This } \\
\text { Study) }\end{array}$ & $19.1 \pm 0.6$ & $29.2 \pm 0.9$ & $7.1 \pm 0.5$ & $7.4 \pm 0.4$ & $27.6 \pm 1.4$ & $28.4 \pm 1.2$ \\
\hline $660 \mathrm{BCE}^{13}$ & $12.5 \pm 1.1$ & $19.2 \pm 2.1$ & $11.4 \pm 0.6$ & $9.0 \pm 0.4$ & $23.9 \pm 2.7$ & $20.9 \pm 2.4$ \\
\hline $775 \mathrm{CE})^{48}$ & $17.6 \pm 0.5$ & $26.2 \pm 1.0$ & $10.7 \pm 0.4$ & $9.3 \pm 0.5$ & $31.5 \pm 1.4$ & $29.0 \pm 1.4$ \\
\hline $993 C^{48}$ & $9.6 \pm 0.6$ & $14.0 \pm 1.2$ & $10.3 \pm 0.4$ & $9.0 \pm 0.5$ & $16.5 \pm 1.5$ & $15.2 \pm 1.4$ \\
\hline $1052 C^{17}$ & $5.9 \pm 1.1$ & $10.1 \pm 2.0$ & $10.2 \pm 0.4$ & $9.0 \pm 0.4$ & $11.8 \pm 2.3$ & $11.0 \pm 2.2$ \\
\hline $1279 \mathrm{CE}^{17}$ & $6.5 \pm 1.6$ & $9.2 \pm 2.7$ & $9.6 \pm 0.3$ & $9.2 \pm 0.5$ & $10.4 \pm 3.0$ & $10.1 \pm 2.9$ \\
\hline
\end{tabular}

\section{Materials and Methods}

\section{Sample preparation and measurement}

For the 7176 BCE event dendrochronologically dated wood samples from Ireland, supplied by the University of Belfast, and from the Alps, supplied by the University of Innsbruck, were dissected into annually resolved samples weighing 30 to $60 \mathrm{mg}$.

Typically 54 tree-ring samples with 4 wood blanks ( 2 BC and $2 \mathrm{~KB}$ ) and 21515 CE reference samples ${ }^{49}$ each weighing 30-60 mg, were prepared in $15 \mathrm{ml}$ glass test tubes together in a batch (making 60 in total). In a slightly modified procedure following Němec et al. ${ }^{50}$, samples were first soaked in $5 \mathrm{ml} 1$ $\mathrm{M} \mathrm{NaOH}$ over night at $70^{\circ} \mathrm{C}$ in an oven. Then the samples were treated with $1 \mathrm{M} \mathrm{HCl}$ and $1 \mathrm{M} \mathrm{NaOH}$ for 1 hour each at $70^{\circ} \mathrm{C}$ in a heat block, before they were bleached at a pH of 2-3 with $0.35 \mathrm{M} \mathrm{NaClO}_{4}$ at $70^{\circ} \mathrm{C}$ for 2 hours. The remaining white holo-cellulose was then freeze-dried overnight.

About $2.5 \mathrm{mg}$ dried holo-cellulose was wrapped in cleaned Al capsules $\mathrm{s}^{51}$ and converted to graphite using the automated graphitization line $A E^{52}$. A measurement set was made up of 3 oxalic acid 1 (OX1) and 4 oxalic acid 2 (OX2) standards, 27 samples, 2 cellulose blanks, 2 chemical blanks, and 2 1515 CE reference samples (individual cellulose preparations of the $1515 \mathrm{CE}$ reference is used for at least two measurements) and measured in the MICADAS accelerator mass spectrometer ${ }^{53}$. Two measurement sets were typically prepared from one set of samples within a week and subsequently measured. A second graphite sample was subsequently prepared and measured from one third of the prepared cellulose samples for quality control purposes. 
Two internal wood reference materials from $1515 \mathrm{CE}$ (Pine and Oak) and two different radiocarbon free wood blanks (Kauri Stage 7, KB, and Brown Coal, BC, from Reichwalde) were repetitively analyzed together with the annual samples. While the wood-blanks were used for blank subtraction in the data evaluation process, the 1515 CE references were used for quality control only.

Several samples were repetitively measured, and a chi squared analysis showed that the repeated measurements were generally in good agreement with one another. The resulting chi square values of the different chronologies are shown in Table 2. Small observed differences are likely due to wood anatomical effects or due to the limitations of cutting tree-rings accurately for species with narrow tree-rings (Supplements S1). The high overall $\chi^{2}$ value events are likely due to regional offset ${ }^{48}$ and the earlier increase signal in the Bristlecone Pine chronology in the 5259 BCE event.

Table 2 Statistical analysis of the repeated measurements of the different chronologies

\begin{tabular}{|l|l|l|l|}
\hline & \multicolumn{1}{|c|}{$\chi^{2}$} & \multicolumn{1}{c|}{ Deg. Of freedom } & \multicolumn{1}{c|}{$P\left(\chi^{2}>\right)$ value } \\
\hline All (7176 BCE) & 255.3 & 202 & 0.01 \\
\hline Alpine Larch (7176 BCE) & 6.3 & 6 & 0.39 \\
\hline $\begin{array}{l}\text { German Oak (7176 } \\
\text { BCE) }\end{array}$ & 112.6 & 93 & 0.08 \\
\hline $\begin{array}{l}\text { Bristlecone Pine (7176 } \\
\text { BCE) }\end{array}$ & 12.4 & 13 & 0.50 \\
\hline All (5259 BCE) & 254.0 & 216 & 0.04 \\
\hline Irish Oak (5259 BCE) & 89.0 & 82 & 0.28 \\
\hline Alpine Larch(5259 BCE) & 15.9 & 13 & 0.25 \\
\hline $\begin{array}{l}\text { Siberian Larch (5259 } \\
\text { BCE) }\end{array}$ & 10.2 & 24 & 0.99 \\
\hline $\begin{array}{l}\text { Bristlecone Pine (5259 } \\
\text { BCE) }\end{array}$ & 16.6 & 24 & 0.87 \\
\hline
\end{tabular}

\section{Modeling}

To model the carbon cycle an improved carbon box model based on the model of Güttler et al. ${ }^{54}$ was used (Supplementary Fig 2). The model of Güttler uses 11 Boxes to simulate the exchange between the global atmosphere biosphere and Oceans. To model the northern and southern hemispheres separately our model was extended to 22 boxes (11 boxes for each hemisphere). The carbon content of each box is distributed according to the respective relative carbon reservoir masses of the corresponding hemisphere. Radiocarbon is produced in the stratosphere and the troposphere of both hemispheres, where $70 \%$ is produced in the Stratosphere and $30 \%$ in the Troposphere. The fluxes were adjusted to ensure a correct $\Delta^{14} \mathrm{C}$ offset between the northern and southern troposphere. Seasonal variability of fluxes was not considered in the model.

The ${ }^{12} \mathrm{C}$ and ${ }^{14} \mathrm{C}$ content of each box after a time step is calculated with

$$
\begin{aligned}
& N_{i}^{12}(t+\Delta t)=N_{i}^{12}(t)+d N_{i}^{12}(t) \Delta t \\
& N_{i}^{14}(t+\Delta t)=N_{i}^{14}(t)+d N_{i}^{14}(t) \Delta t \\
& d N_{i}^{12}(t)=\sum_{j} F_{j i}^{12}(t)-\sum_{j} F_{i j}^{12}(t)
\end{aligned}
$$




$$
d N_{i}^{14}(t)=-\lambda N_{i}+\sum_{j} F_{j i}^{14}(t)-\sum_{j} F_{i j}^{14}(t)+P_{i}(t)+P_{s t, i}
$$

Here $N_{i}^{12,14}$ is the $C^{12,14}$ content of each box in $\mathrm{Gt}$ and $\lambda$ is the decay constant of ${ }^{14} \mathrm{C}$. The time step $\Delta t$ was chosen to be one month for all the following simulations. The ${ }^{14} \mathrm{C}$ and ${ }^{12} \mathrm{C}$ fluxes are given by the following:

$$
F_{i j}^{12}(t)=F_{i j, s t} \frac{N_{i}^{12}(t)}{N_{i, s t}^{12}}, F_{i j}^{14}(t)=F_{i j, s t} \frac{N_{i}^{12}(t)}{N_{i, s t}^{12}} \frac{N_{i}^{14}(t)}{N_{i}^{12}(t)} \frac{m_{14}}{m_{12}}=F_{i j, s t} \frac{N_{i}^{14}(t)}{N_{i, s t}^{12}} \frac{m_{14}}{m_{12}}
$$

Here $F_{i j, s t}$ are the fluxes given in Supplementary Figure 2. The fluxes are scaled depending on the deviation from the Holocene steady state $N_{i, s t}^{12}$. The steady state was computed by simulating $200^{\prime} 000$ years with the constant production rate $p_{s t}=1.76 \frac{\mathrm{at}}{\mathrm{cm}^{2} \mathrm{~s}}$. The model does not consider any isotopic fractionation and thus the ${ }^{14} \mathrm{C}$ fluxes scale just as the ${ }^{12} \mathrm{C}$ fluxes.

With this a general expression for all boxes at any time can be achieved.

$$
\begin{gathered}
N(t+\Delta t)=N(t)+\left(\Lambda N(t)+F^{T}(t) \mathbf{1}-F(t) \mathbf{1}+P(t)+P_{s t}\right) \Delta t \\
F=\left[\begin{array}{cc}
F^{12}(t) & 0 \\
0 & F^{14}(t)
\end{array}\right], \Lambda=\left[\begin{array}{cc}
0 & 0 \\
0 & -\lambda
\end{array}\right], N(t)=\left(\begin{array}{c}
N^{12} \\
N^{14}
\end{array}\right), \mathbf{1}_{i}=1 \text { for all } i \\
P(t)=V p(t), P_{\text {st }}=V p_{\text {st }} \\
V_{i}=\left\{\begin{array}{c}
0.5 \cdot 0.7, \text { if } i=\text { Stratosphere } N, S \\
0.5 \cdot 0.3, \text { if } i=\text { Troposphere } N, S \\
0, \text { else }
\end{array}\right.
\end{gathered}
$$

The $\Delta^{14} \mathrm{C}$ of each box for the simulation is calculated by the following expression:

$$
\Delta^{14} C_{i}(t)=\frac{\frac{N_{i}^{14}(t)}{N_{i}^{12}(t)}-\frac{N_{T N, s t}^{14}}{N_{T N, s t}^{12}}}{\frac{N_{T N, s t}^{14}}{N_{T N, s t}^{12}}} \cdot 1000
$$

Where $N_{T N, s t}^{12,14}$ are the steady state ${ }^{12,14} \mathrm{C}$ contents of the northern troposphere.

To get a reasonable start state at a given time the production rate for the whole IntCal13 record has been calculated and the simulated state can be loaded at any time before $1950 \mathrm{CE}$.

The events were evaluated by generating 1000 realizations of the data distributed with the errors of the measurements. For each realization a Gaussian shaped production spike was fitted and the additional production was extracted by integrating the Gaussian production. Since the energy spectrum of the SEPs is softer than the one of the galactic cosmic rays the excess production of the event was mainly produced in the stratosphere $(90 \%)$ and only $10 \%$ in the troposphere. The errors were estimated by using the widths of the resulting distributions.

\section{Geomagnetic field correction}

Since the production of ${ }^{14} \mathrm{C}$ in the Earth's atmosphere is affected by geomagnetic shielding of the flux of SEPs, this effect needs to be accounted for in such a way that all the events are normalized to the same reference standard, specifically to the modern conditions with the dipole moment $M=7.8 \cdot 10^{22}$ $A \cdot m^{255}$. The geomagnetic field has a very complex structure at the Earth's surface ${ }^{56}$, but for energetic 
particles, the dipole moment is the most important since higher momenta decay faster with distance, and the eccentric+tilted dipole approximation is widely used ${ }^{57}$. Since the true dipole moment is difficult to determine in the past, before the era of direct measurements, an approximation of the virtual axial dipole moment (VADM) is reconstructed from paleo- and archeo-magnetic models ${ }^{58}$. Accordingly, the geomagnetic-shielding effect on energetic particles is often quantified via the VADM value of $M$. The modern (epoch 2000) dipole moment is $M_{0}=7.8 \cdot 10^{22} \mathrm{~A} \cdot \mathrm{m}^{2}$. Here we normalize the apparent ${ }^{14} \mathrm{C}$ production $Q$ during different events to the standard modern conditions, viz. the production that would be if the event took place nowadays. For that, we modelled the dependence of $Q$ on $M$ using a broad range of SEP spectra measured during the recent decades ${ }^{59}$. The spectra are bound between the hardest known spectrum of SEP event on 23-Feb-1956 $\left(\mathrm{GLE} 05^{60}\right)$ and the softest strong-event spectrum of 04-Aug-1972 (GLE $24^{60}$ ), as shown in EDFig.4a. The same plot shows also the global yield function, denoted as $Y_{p}(E)$, of ${ }^{14} \mathrm{C}$ for three VADM values of $M=3,6$ and $9\left(\times 10^{22} \mathrm{~A} \cdot \mathrm{m}^{2}\right)$. The global production function is defined as

$$
Y_{p}(E, M)=\int_{0}^{\pi / 2} Y(E) \cdot H(E, M, \theta) \cdot \sin (\theta) \cdot d \theta
$$

where $Y(E)$ is the columnar yield function of ${ }^{14} \mathrm{C}$ by protons with energy $E$ in the Earth's atmosphere ${ }^{61}$, $H(E)$ is a step-like magnetospheric transmissivity function taking the value of 0 for $E<E_{c}$ and 1 otherwise, where $E_{c}$ is the energy corresponding to the local geomagnetic rigidity cutoff defined by the dipole moment $M$ and the polar angle (co-latitude) $\vartheta$. The production is higher for a weaker geomagnetic field (smaller values of $M$ ) and vice versa. The production of ${ }^{14} \mathrm{C}$ by a specific SEP event with a given proton spectrum $J_{p}$ is defined as the integral of the product of the yield function and the energy spectrum of particles.

$$
Q(M)=\int_{0}^{\infty} Y_{p}(E, M) \cdot J_{p}(E) \cdot d E
$$

The dependence of $Q$ on $M$ is shown in EDFig.4b for the two analyzed SEP spectra. In order to compensate for the variable geomagnetic field, we introduce the correction factor, which relates the ${ }^{14} \mathrm{C}$ production at the VADM $M$ to that at the reference field $M_{0}$ :

$$
C=\frac{Q\left(M_{0}\right)}{Q(M)} .
$$

The correction factor is shown in EDFig.4c for the two SEP spectra. Although the spectra are essentially different (panel a) and the isotope production for the two events is different too (panel b), the correction factor appears robust against the exact spectral shape. This correction factor was further applied to compare the strength of all studied events to the standard conditions, as shown in Table 1.

Reconstructions of the geomagnetic field in the past is a difficult task, and the result can be uncertain. To cover a possible range of VADM values we took a conservative approach and considered two paleomagnetic reconstructions for the last millennia, as shown in EDFig.5: a recent GGF100k paleomagnetic model by Panovska et al. ${ }^{41}$ and a reconstruction by Knudsen et al. ${ }^{42}$ based on the GEOMAGIA50 database. Although there are many other paleomagnetic reconstructions, these two cover the full range of uncertainties.

The uncertainties of the corrected for the VADM changes ${ }^{14} \mathrm{C}$ production (last two columns in Table 1) are mostly defined by the uncertainties of the actual production (column 3 ) and VADM uncertainties (columns 4 and 5). The resultant uncertainty of the corrected production was assessed 
using the Monte-Carlo method by randomly picking pairs of $M$ and $Q$ from the normally distributed values within the ranges shown in Table 1 and computing the mean and the standard deviation of the corrected $Q$ values.

\section{Author contribution}

L.W., M.C. and N.B. designed the study with input from H.-A.S., R.M. and F.A.. A.B., D.B., H.-H.L., K.N, T.P., C.L.P., M.W.S. and R.H. supplied the annually resolved tree-ring samples and are responsible for the documentation of the dendrochronology. Radiocarbon measurements and analyses were performed by N.B., L.W. and T.K.. The modelling and interpretation of the ${ }^{14} \mathrm{C}$ data were done by N.B, M.C., and L.W. with input from I.U., F.A., R.M., H.-A.S., F.M. and C.P.. N.B, M.C., and L.W. wrote the manuscript with input from all other authors.

\section{Acknowledgement}

The Laboratory of Ion Beam Physics is partially funded by its consortium partners PSI, EAWAG, and EMPA. N.B. is funded by the Swiss National Science Foundation (SNSF grant \#SNF 197137). We thank Bisserka Gaydarska for sub-sampling the inter-laboratory replicates from M49, M234, Q2729 and Q2750, Cathy Tyers for reviewing the dating of the Irish and German samples, and Alexander Land for assistance in dating sample M49. P.F. received funding from the SNF Sinergia project CALDERA (no. 183571). R.H. is funded by Russian Science Foundation (grant \# 21-14-00330). I.U. acknowledges the support from the Academy of Finland (grant 321882 ESPERA).

\section{Competing interest}

The authors declare no competing interests

\section{References}

1 Desai, M. \& Giacalone, J. Large gradual solar energetic particle events. Living Reviews in Solar Physics 13, 3, doi:10.1007/s41116-016-0002-5 (2016).

2 Eastwood, J. P. et al. Quantifying the Economic Value of Space Weather Forecasting for Power Grids: An Exploratory Study. Space Weather 16, 2052-2067, doi:10.1029/2018SW002003 (2018).

3 Council, N. R. Severe Space Weather Events-Understanding Societal and Economic Impacts: A Workshop Report: Extended Summary. (The National Academies Press, 2009).

4 Green, J. L., Boardsen, S., Odenwald, S., Humble, J. \& Pazamickas, K. A. Eyewitness reports of the great auroral storm of 1859. Advances in Space Research 38, 145-154, doi:10.1016/j.asr.2005.12.021 (2006).

5 Fry, E. K. The risks and impacts of space weather: Policy recommendations and initiatives. Space Policy 28, 180-184, doi:10.1016/j.spacepol.2012.06.005 (2012).

6 Forbush, S. E. Three Unusual Cosmic-Ray Increases Possibly Due to Charged Particles from the Sun. Physical Review 70, 771-772, doi:10.1103/PhysRev.70.771 (1946).

7 Vlahos, L., Anastasiadis, A., Papaioannou, A., Kouloumvakos, A. \& Isliker, H. Sources of solar energetic particles. Philosophical Transactions of the Royal Society A: Mathematical, Physical and Engineering Sciences 377, 20180095, doi:10.1098/rsta.2018.0095 (2019). in The hostile Sun (eds Fusa Miyake, llya Usoskin, \& Stepan Poluianov) (IOP Publishing, 2019).

9 Usoskin, I. G. et al. Revisited Reference Solar Proton Event of 23 February 1956: Assessment of the Cosmogenic-Isotope Method Sensitivity to Extreme Solar Events. Journal of Geophysical Research: Space Physics 125, e2020JA027921, doi:10.1029/2020JA027921 (2020). 
Maehara, H. et al. Superflares on solar-type stars. Nature 485, 478-481, doi:10.1038/nature11063 (2012).

11 Reinhold, T. et al. The Sun is less active than other solar-like stars. Science 368, 518-521, doi:10.1126/science.aay3821 (2020).

12 Beer, J., Vonmoos, M. \& Muscheler, R. Solar variability over the past several millennia. Space Science Reviews 125, 67-79, doi:10.1007/S11214-006-9047-4 (2006).

13 Sakurai, H. et al. Prolonged production of $14 \mathrm{C}$ during the $660 \mathrm{BCE}$ solar proton event from Japanese tree rings. Scientific Reports 10, 660, doi:10.1038/s41598-019-57273-2 (2020). Miyake, F., Nagaya, K., Masuda, K. \& Nakamura, T. A signature of cosmic-ray increase in AD 774-775 from tree rings in Japan. Nature 486, 240-242, doi:10.1038/Nature11123 (2012). Usoskin, I. G. A History of Solar Activity over Millennia. Living Reviews in Solar Physics 10, 7-+, doi:10.1007/s41116-017-0006-9 (2013).

16 Potgieter, M. S. Solar Modulation of Cosmic Rays. Living Reviews in Solar Physics 10, 3, doi:10.12942/Irsp-2013-3 (2013).

17 Brehm, N. et al. Eleven-year solar cycles over the last millennium revealed by radiocarbon in tree rings. Nature Geoscience 14, 10-15, doi:10.1038/s41561-020-00674-0 (2021).

18 Muscheler, R. et al. Solar activity during the last $1000 \mathrm{yr}$ inferred from radionuclide records. Quaternary Science Reviews 26, 82-97, doi:10.1016/J.Quascirev.2006.07.012 (2007). Park, J., Southon, J., Fahrni, S., Creasman, P. P. \& Mewaldt, R. Relationship between Solar Activity and delta c-14 peaks in AD 775, AD 994, AND 660 BC. Radiocarbon 59, 1147-1156, doi:10.1017/Rdc.2017.59 (2017). Mekhaldi, F. et al. Multiradionuclide evidence for the solar origin of the cosmic-ray events of AD 774/5 and 993/4. Nature Communications 6, 8611, doi:10.1038/ncomms9611 (2015). Miyake, F. et al. Large ${ }^{14} \mathrm{C}$ excursion in $5480 \mathrm{BC}$ indicates an abnormal sun in the midHolocene. Proceedings of the National Academy of Sciences 114, 881-884, doi:10.1073/pnas.1613144114 (2017).

22 Usoskin, I. G., Solanki, S. K., Kovaltsov, G. A., Beer, J. \& Kromer, B. Solar proton events in cosmogenic isotope data. Geophys Res Lett 33, doi:10.1029/2006GL026059 (2006). Miyake, F. et al. A Single-Year Cosmic Ray Event at 5410 BCE Registered in 14C of Tree Rings. Geophys Res Lett 48, e2021GL093419, doi:10.1029/2021GL093419 (2021).

24 Timothy Jull, A. J. et al. Rapid 14C excursion at 3372-3371 BCE not observed at two different locations. Nature Communications 12, 712, doi:10.1038/s41467-020-20695-y (2021). Berggren, A.-M. et al. A 600-year annual 10Be record from the NGRIP ice core, Greenland. Geophys Res Lett 36, doi:10.1029/2009GL038004 (2009).

26 Beer, J. et al. Use of 10Be in polar ice to trace the 11-year cycle of solar activity. Nature 347, 164-166, doi:10.1038/347164a0 (1990).

27 Friedrich, M. et al. The 12,460-year Hohenheim Oak and Pine Tree-Ring Chronology from Central Europe-A Unique Annual Record for Radiocarbon Calibration and Paleoenvironment Reconstructions. 46, 1111 - 1122, doi:10.1017/s003382220003304x (2004).

28 Reimer, P. J. et al. The IntCal20 Northern Hemisphere Radiocarbon Age Calibration Curve (055 cal kBP). Radiocarbon 62, 725-757, doi:10.1017/RDC.2020.41 (2020).

29 O'Hare, P. et al. Multiradionuclide evidence for an extreme solar proton event around 2,610 B.P. ( approximately 660 BC). Proc Natl Acad Sci U S A 116, 5961-5966, doi:10.1073/pnas.1815725116 (2019).

30 Adolphi, F. \& Muscheler, R. Synchronizing the Greenland ice core and radiocarbon timescales over the Holocene - Bayesian wiggle-matching of cosmogenic radionuclide records. Clim. Past 12, 15-30, doi:10.5194/cp-12-15-2016 (2016).

31 Veres, D. et al. The Antarctic ice core chronology (AICC2012): an optimized multi-parameter and multi-site dating approach for the last 120 thousand years. Clim. Past 9, 1733-1748, doi:10.5194/cp-9-1733-2013 (2013).

32 Yiou, F. et al. Beryllium 10 in the Greenland Ice Core Project ice core at Summit, Greenland. Journal of Geophysical Research: Oceans 102, 26783-26794, doi:10.1029/97JC01265 (1997). 
33 Steinhilber, F. et al. 9,400 years of cosmic radiation and solar activity from ice cores and tree rings. Proceedings of the National Academy of Sciences 109, 5967, doi:10.1073/pnas.1118965109 (2012).

34 Muscheler, R. et al. Changes in the carbon cycle during the last deglaciation as indicated by the comparison of $10 \mathrm{Be}$ and $14 \mathrm{C}$ records. Earth and Planetary Science Letters 219, 325-340, doi:10.1016/S0012-821X(03)00722-2 (2004).

Denaire, A. et al. The Cultural Project: Formal Chronological Modelling of the Early and Middle Neolithic Sequence in Lower Alsace. Journal of Archaeological Method and Theory 24, 1072-1149, doi:10.1007/s10816-016-9307-x (2017).

36 Jakucs, J. et al. Between the Vinča and Linearbandkeramik Worlds: The Diversity of Practices and Identities in the 54th-53rd Centuries cal BC in Southwest Hungary and Beyond. Journal of World Prehistory 29, 267-336, doi:10.1007/s10963-016-9096-x (2016).

37 Jakucs, J. et al. Rows with the neighbours: the short lives of longhouses at the Neolithic site of Versend-Gilencsa. Antiquity 92, 91-117, doi:10.15184/aqy.2017.218 (2018).

38 Usoskin, I. G. \& Kovaltsov, G. A. Occurrence Of Extreme Solar Particle Events: Assessment From Historical Proxy Data. The Astrophysical Journal 757, 92, doi:10.1088/0004637x/757/1/92 (2012).

39 Nicolussi, K. et al. A 9111 year long conifer tree-ring chronology for the European Alps: a base for environmental and climatic investigations. The Holocene 19, 909-920, doi:10.1177/0959683609336565 (2009).

40 Nicolussi, K., Weber, G., Patzelt, G. \& Thurner, A. A question of time: extension of the Eastern Alpine Conifer Chronology back to 10071 b2k. GFZ Potsdam, Scientific Technical Report STR15, Potsdam, 69-73 (2015).

41 Panovska, S., Constable, C. G. \& Korte, M. Extending Global Continuous Geomagnetic Field Reconstructions on Timescales Beyond Human Civilization. Geochemistry, Geophysics, Geosystems 19, 4757-4772, doi:10.1029/2018GC007966 (2018).

42 Knudsen, M. F. et al. Variations in the geomagnetic dipole moment during the Holocene and the past 50 kyr. Earth and Planetary Science Letters 272, 319-329, doi:10.1016/j.epsl.2008.04.048 (2008).

43 Salzer, M. W., Pearson, C. L. \& Baisan, C. H. Dating the Methuselah Walk Bristlecone Pine Floating Chronologies. Tree-Ring Research 75, 61-66, doi:10.3959/1536-1098-75.1.61 (2019).

44 Adolphi, F. et al. Connecting the Greenland ice-core and U/Th timescales via cosmogenic radionuclides: testing the synchroneity of Dansgaard-Oeschger events. Clim. Past 14, 17551781, doi:10.5194/cp-14-1755-2018 (2018).

45 Cliver, E. W., Hayakawa, H., Love, J. J. \& Neidig, D. F. On the Size of the Flare Associated with the Solar Proton Event in 774 AD. The Astrophysical Journal 903, 41, doi:10.3847/15384357/abad93 (2020).

46 Dyer, C. S., Lei, F., Clucas, S. N., Smart, D. F. \& Shea, M. A. Solar particle enhancements of single-event effect rates at aircraft altitudes. IEEE Transactions on Nuclear Science 50, 20382045, doi:10.1109/TNS.2003.821375 (2003).

47 Cannon, P., Angling, M., L., B. \& al., e. Extreme space weather:impacts on engineered systems and infrastructure (Royal Academy of Engineering, 2013).

48 Büntgen, U. et al. Tree rings reveal globally coherent signature of cosmogenic radiocarbon events in 774 and 993 CE. Nature Communications 9, doi:10.1038/s41467-018-06036-0 (2018).

49 Sookdeo, A. et al. Quality Dating: A well-defined protocol implemented at ETH for highprecision 14C dates tested on Late Glacial wood. Radiocarbon, doi:10.1017/RDC.2019.132 (2020).

50 Němec, M., Wacker, L., Hajdas, I. \& Gäggeler, H. Alternative Methods for Cellulose Preparation for AMS Measurement. Radiocarbon 52, 1358-1370, doi:10.1017/s0033822200046440 (2016). 
51 Welte, C. et al. Towards the limits: Analysis of microscale C-14 samples using EA-AMS. Nuclear Instruments \& Methods in Physics Research Section B-Beam Interactions with Materials and Atoms 437, 66-74, doi:10.1016/j.nimb.2018.09.046 (2018).

52 Wacker, L., Nemec, M. \& Bourquin, J. A revolutionary graphitisation system: Fully automated, compact and simple. Nuclear Instruments and Methods in Physics Research Section B: Beam Interactions with Materials and Atoms 268, 931-934, doi:10.1016/j.nimb.2009.10.067 (2010).

53 Synal, H. A., Stocker, M. \& Suter, M. MICADAS: A new compact radiocarbon AMS system. Nuclear Instruments \& Methods in Physics Research Section B-Beam Interactions with Materials and Atoms 259, 7-13, doi:Doi 10.1016/J.Nimb.2007.01.138 (2007).

54 Guttler, D. et al. Rapid increase in cosmogenic 14C in AD 775 measured in New Zealand kauri trees indicates short-lived increase in $14 \mathrm{C}$ production spanning both hemispheres. Earth and Planetary Science Letters 411, 290-297, doi:10.1016/j.epsl.2014.11.048 (2015).

55 Usoskin, I. G. et al. Solar cyclic activity over the last millennium reconstructed from annual 14C dataᄎ. A\&A 649, A141 (2021).

56 Alken, P. et al. International Geomagnetic Reference Field: the thirteenth generation. Earth, Planets and Space 73, 49, doi:10.1186/s40623-020-01288-x (2021).

57 Usoskin, I. G., Mironova, I. A., Korte, M. \& Kovaltsov, G. A. Regional millennial trend in the cosmic ray induced ionization of the troposphere. Journal of Atmospheric and SolarTerrestrial Physics 72, 19-25, doi:10.1016/j.jastp.2009.10.003 (2010).

58 Korte, M. \& Constable, C. G. The geomagnetic dipole moment over the last 7000 years -new results from a global model. Earth and Planetary Science Letters 236, 348-358, doi:10.1016/j.epsl.2004.12.031 (2005).

59 Koldobskiy, S., Raukunen, O., Vainio, R., Kovaltsov, G. A. \& Usoskin, I. New reconstruction of event-integrated spectra (spectral fluences) for major solar energetic particle events $\star$. $A \& A$ 647, A132 (2021).

60 Raukunen, O. et al. Two solar proton fluence models based on ground level enhancement observations. J. Space Weather Space Clim. 8, A04 (2018).

61 S. V. Poluianov, G. A. K., A. L. M ishev, I. G. Usoskin. Production of cosmogenic isotopes ${ }^{7} \mathrm{Be}$, ${ }^{10} \mathrm{Be},{ }^{14} \mathrm{C},{ }^{22} \mathrm{Na}$, and ${ }^{36} \mathrm{Cl}$ in the atmosphere: Altitudinal profiles of yield functions. journal of Geophysical Research: Atmospheres 121, 8125- 8136, doi:10.1002/2016JD025034 (2016). 
Figures
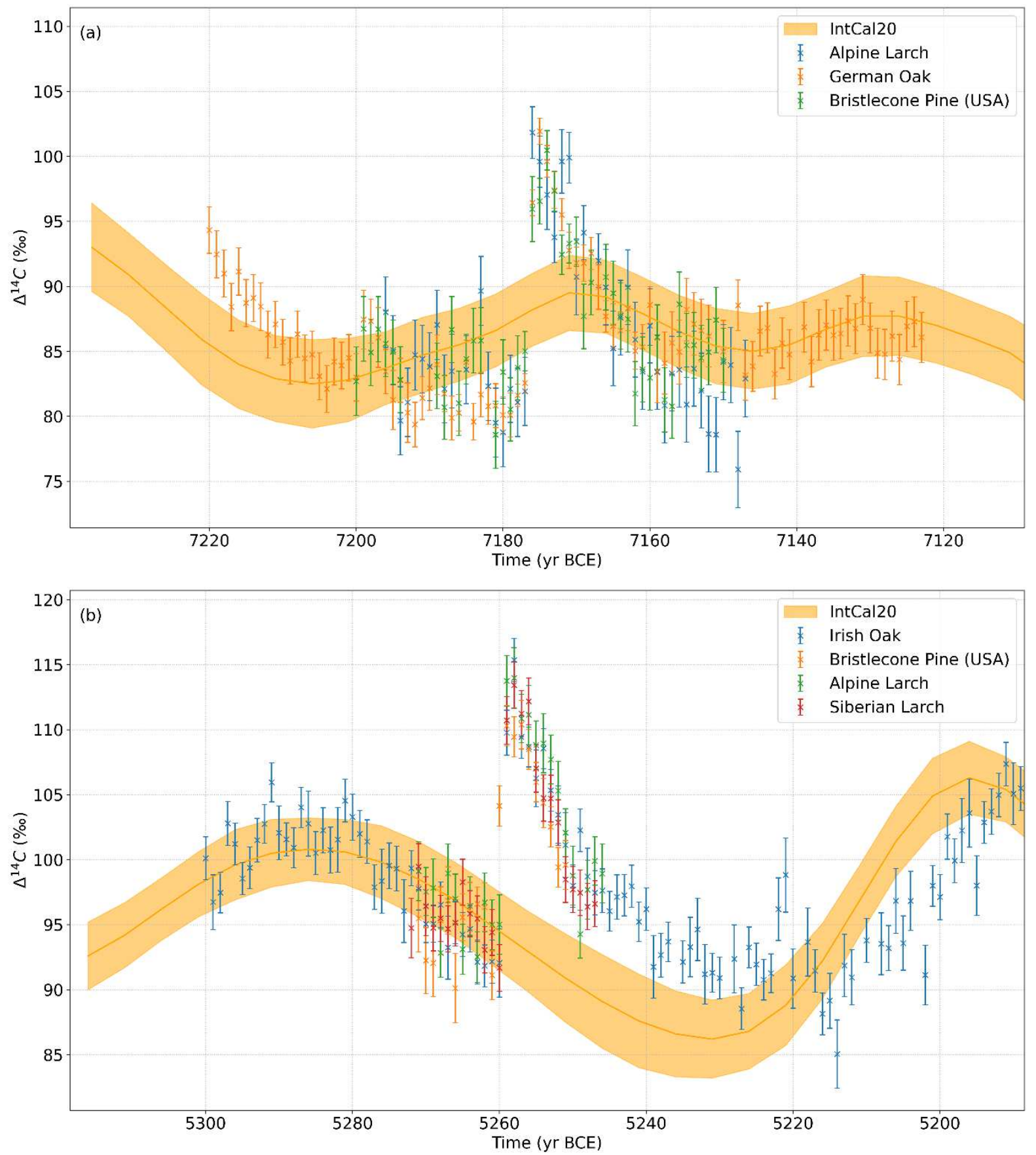

Figure ${ }^{14} \mathrm{C}$ data of the two new events compared to IntCal20. Annual ${ }^{14} \mathrm{C}$ concentrations reported as $\Delta^{14} \mathrm{C}$ with $1-\sigma$ errors from different trees for the two newly found events (7176 BCE (a), 5259 BCE (b)) in comparison with the IntCal20 calibration curve $^{28}$ (orange band). 

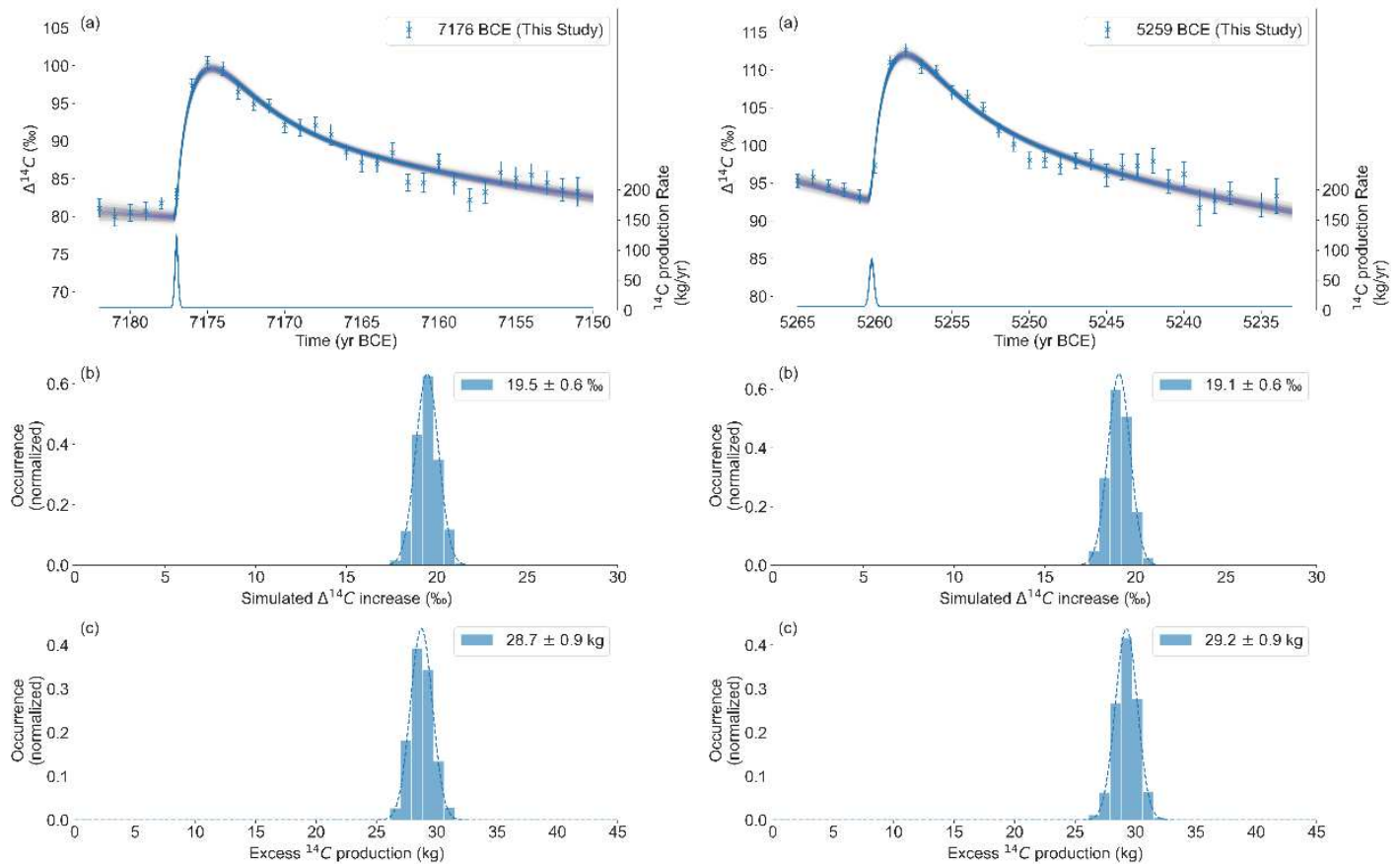

Figure 2 Evaluation procedure of the newly found events. (a) Mean data of the two new events (7176 BCE left, 5259 BCE right) with 1- $\sigma$ errors and result of 1000 Simulations (blue lines) The fitted Gaussian shaped production spikes for all simulations is also shown. (b) Distribution of the simulated $\Delta^{14} \mathrm{C}$ increases (blue bars) with a gaussian fit (dashed line). (c) Distribution of excess ${ }^{14} \mathrm{C}$ production (blue bars) with Gaussian fit (dashed line). 


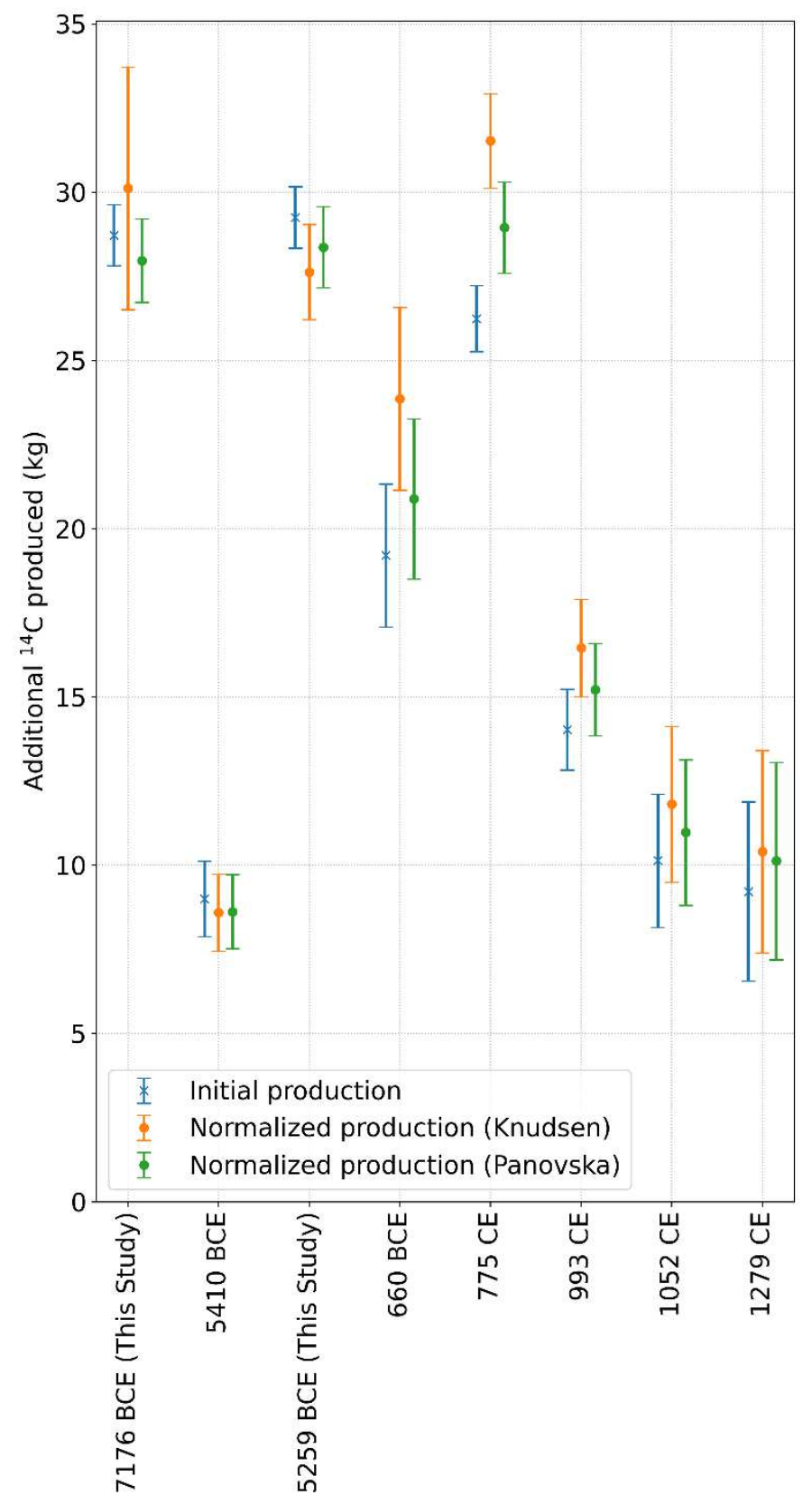

Figure 3 Initial and normalized event productions. Excess ${ }^{14} \mathrm{C}$ produced during the events (blue) in comparison to the excess ${ }^{14} \mathrm{C}$ production normalized to today's geomagnetic field strength using two different records (orange Knudsen ${ }^{42}$, green Panovska ${ }^{41}$ ) with 1- $\sigma$ error bars for all known ${ }^{14} \mathrm{C}$ events.

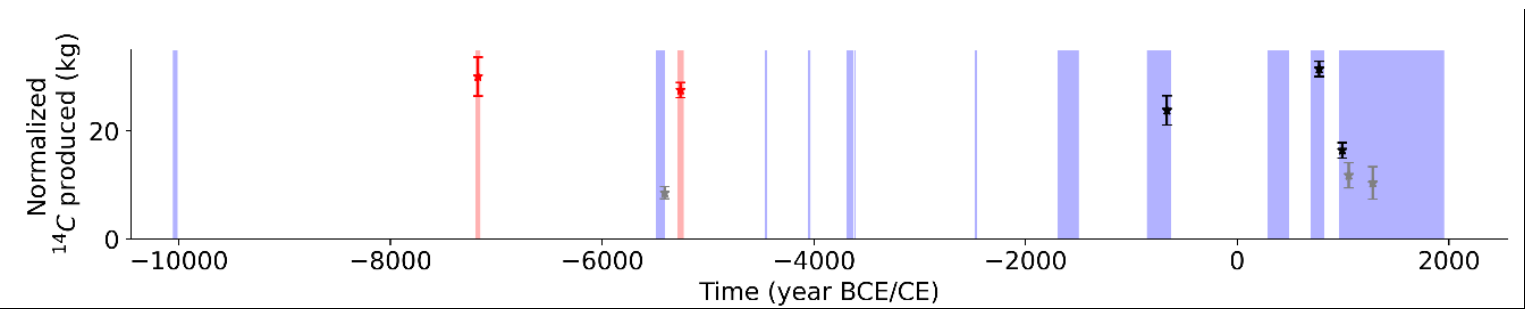

Figure 4 Magnitude and occurrence of all known ${ }^{14} \mathrm{C}$ events over time. Shaded regions mark time periods where IntCal $20^{28}$ (purple) and our data (red) are based on annual or biennial resolution. Data points show the timing of all known (black) and newly identified (red) ${ }^{14} \mathrm{C}$ events and their normalized additional production with 1- $\sigma$ errors. Event candidates are indicated in grey. 
Supplementary figures
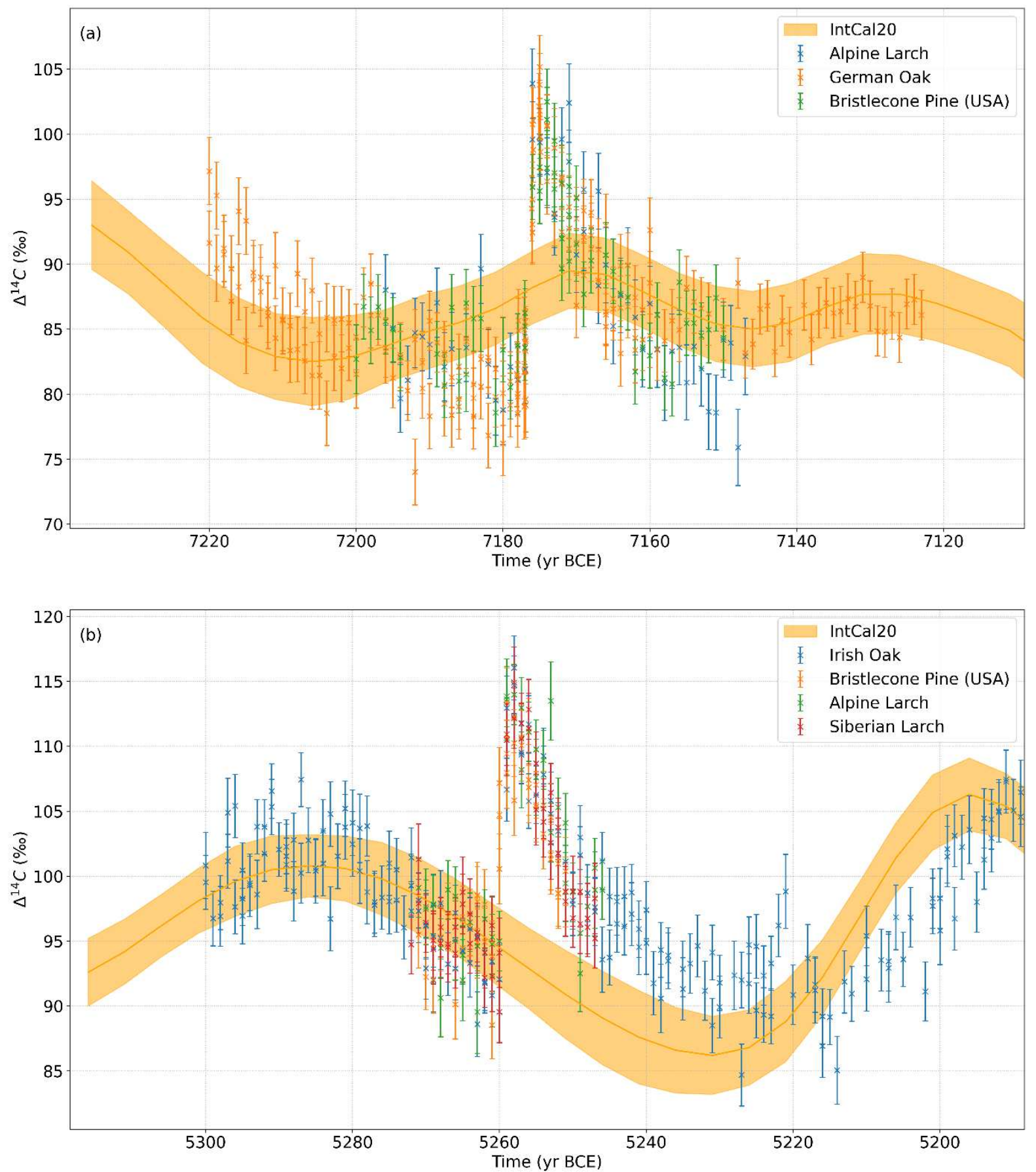

Supplementary Fig. 1 All Measurement results of the 2 new events. ${ }^{14} \mathrm{C}$ measurements with 1- $\sigma$ errors reported as $\Delta^{14} \mathrm{C}$ of the two newly found events (7176 BCE (a), 5259 BCE (b)) in all different trees compared to the IntCal 20 calibration curve ${ }^{28}$ (orange band). The Irish Oak was independently repeated by two different labs (ETH-Zurich, Bristol). 
Southern hemisphere

Northern hemisphere

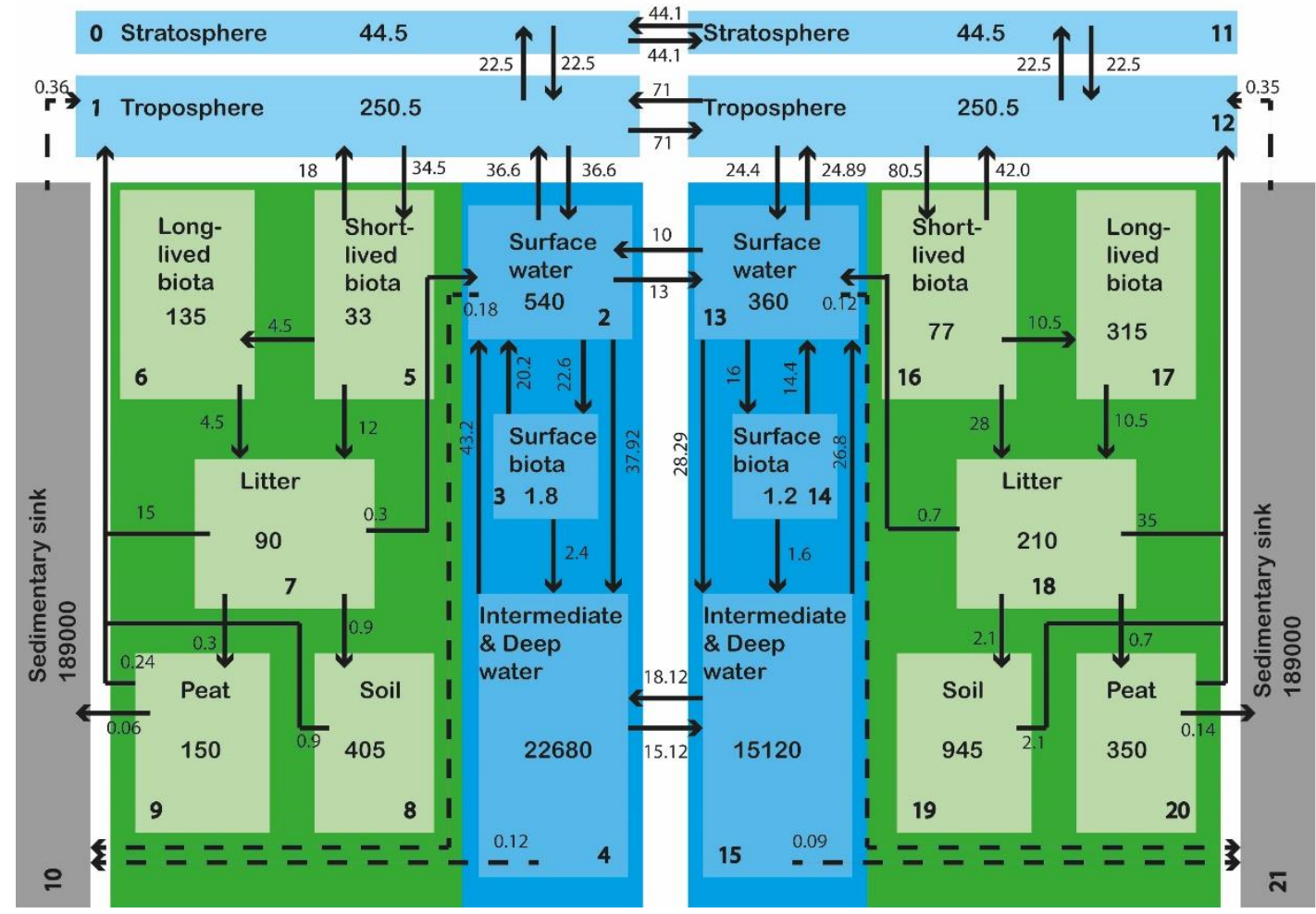

Supplementary Fig. 2 Carbon box model used to reconstruct ${ }^{14} \mathrm{C}$ production. The carbon fluxes between boxes and their carbon contents are given in Gt/yr and Gt. 

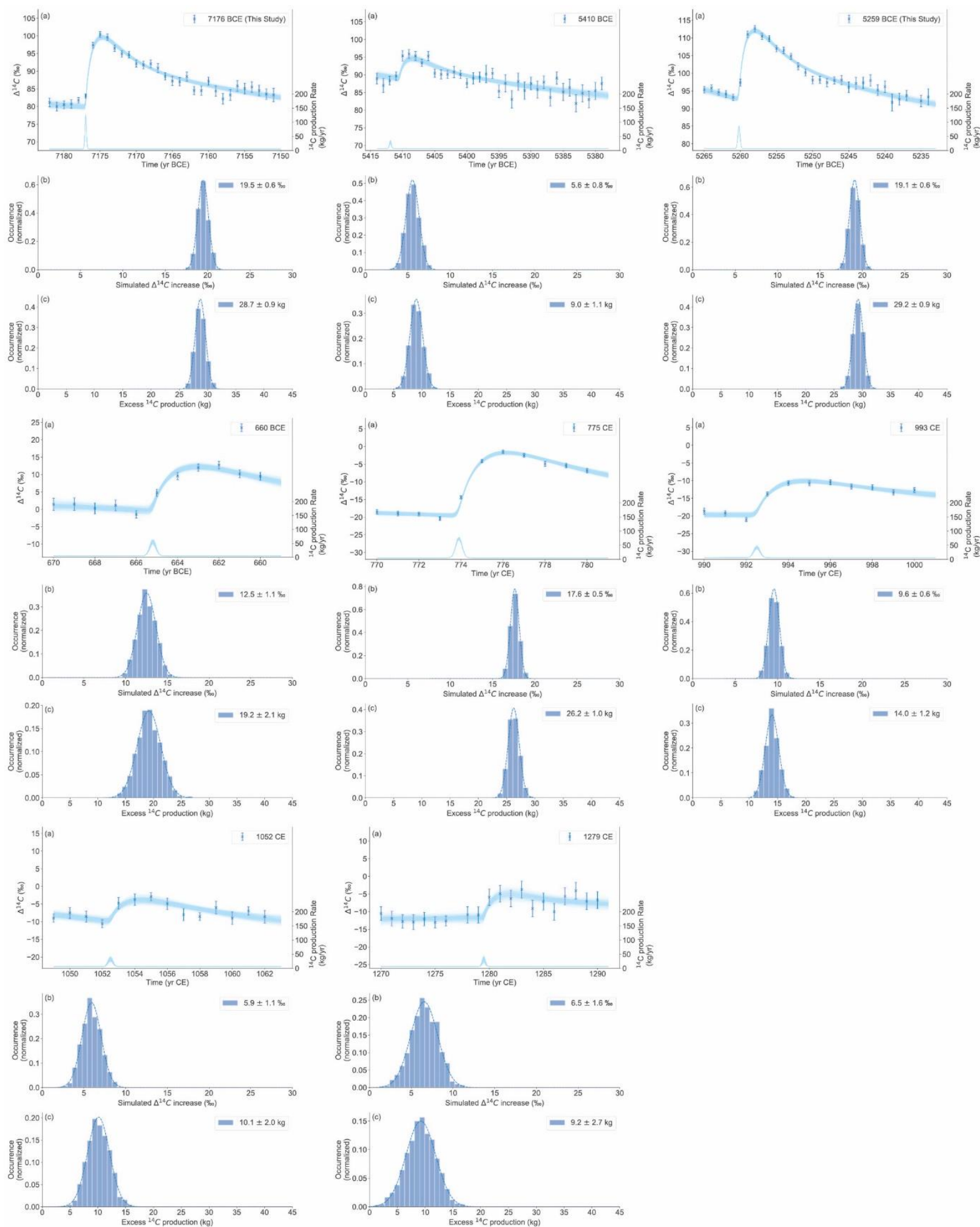

Supplementary Fig. 3 Evaluation of all known ${ }^{14} \mathrm{C}$ events. (a) Mean data of known ${ }^{14} \mathrm{C}$ events with 1- $\sigma$ errors and result of 1000 Simulations. The fitted Gaussian shaped production spikes for all simulations are also shown. (b) Distribution of the simulated $\triangle^{14} \mathrm{C}$ increases (blue bars) with a Gaussian fit (dashed line). (c) Distribution of excess ${ }^{14} \mathrm{C}$ production (blue bars) with Gaussian fit (dashed line).Data Sources: 5410 BCE: Miyake et al.23, 660 BCE: Sakurai et al. ${ }^{13}$, 775 CE and 993 CE: Büntgen et al. ${ }^{48}, 1052 \mathrm{CE}$ and $1279 \mathrm{CE}$ : Brehm et al. ${ }^{17}$. 

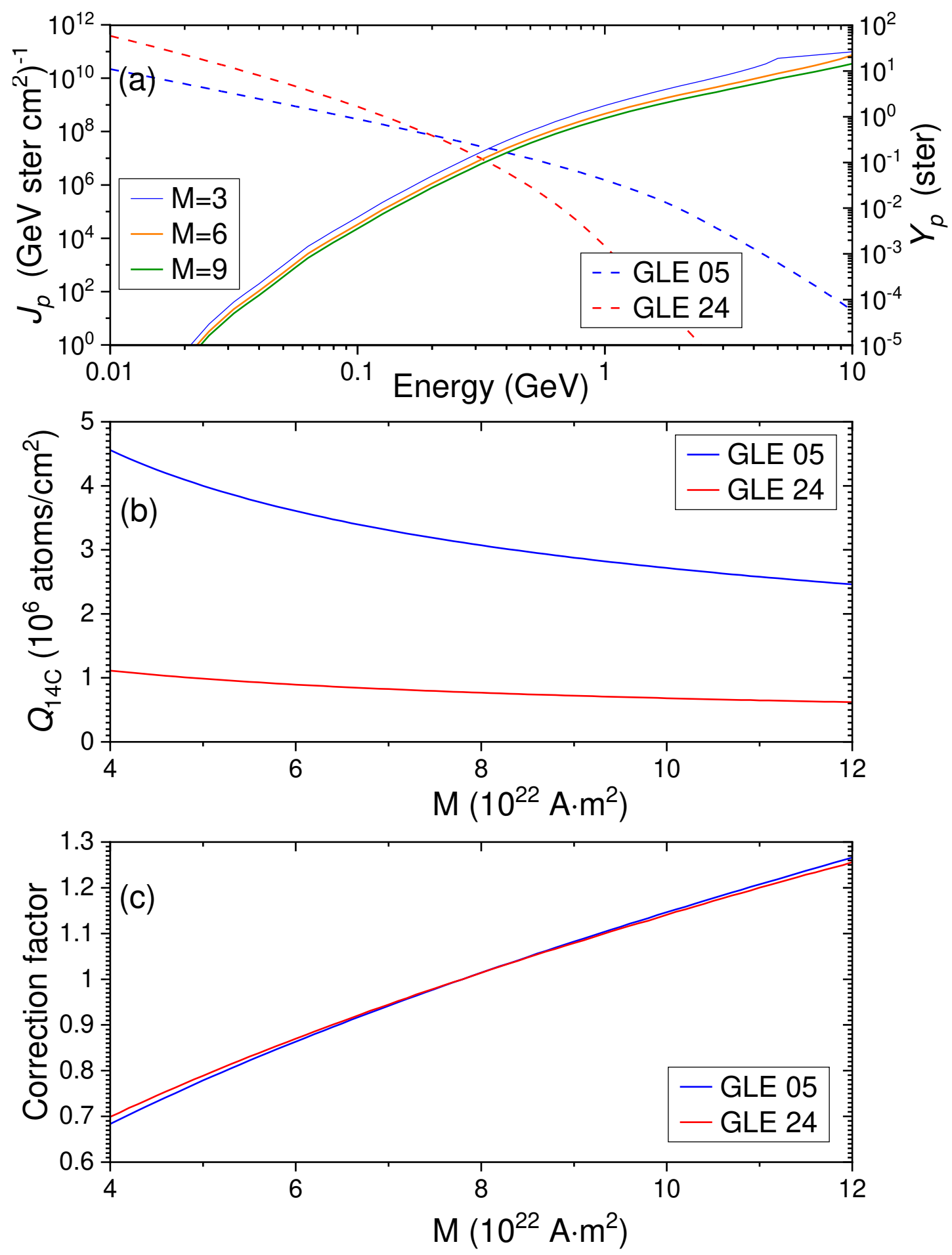

Supplementary Fig. 4 Production of ${ }^{14} \mathrm{C}$ by SEP events for different values of VADM: (a) Global yield functions $\left(Y_{p}\right.$, righthand-side axis) of ${ }^{14} \mathrm{C}$ by protons for three values of VADM $\left(3 x, 6 x\right.$ and $9 \times 10^{22} A m^{2}$ as blue, orange and green solid lines, respectively); as well as spectral omnidirectional fluences (J(E), left-hand-side axis) of SEPs for two bounding cases, the softest and hardest-spectrum known events of 23-Feb-1956 (GLE 05, blue dashed line) and 04-Aug-1972 (GLE 24, red dashed line). (b) Calculated globally-averaged ${ }^{14} C$ production $Q_{14 C}$ during the two SEP events as a function of the geomagnetic field $V A D M$. (c) Correction factor $Q\left(M_{0}\right) / Q(M)$ of the ${ }^{14} C$ production at the VADM value of $M$ to that for a modern geomagnetic field $\left(M_{o}=7.8 \cdot 10^{22} \mathrm{~A} \mathrm{~m}^{2}\right)$. 


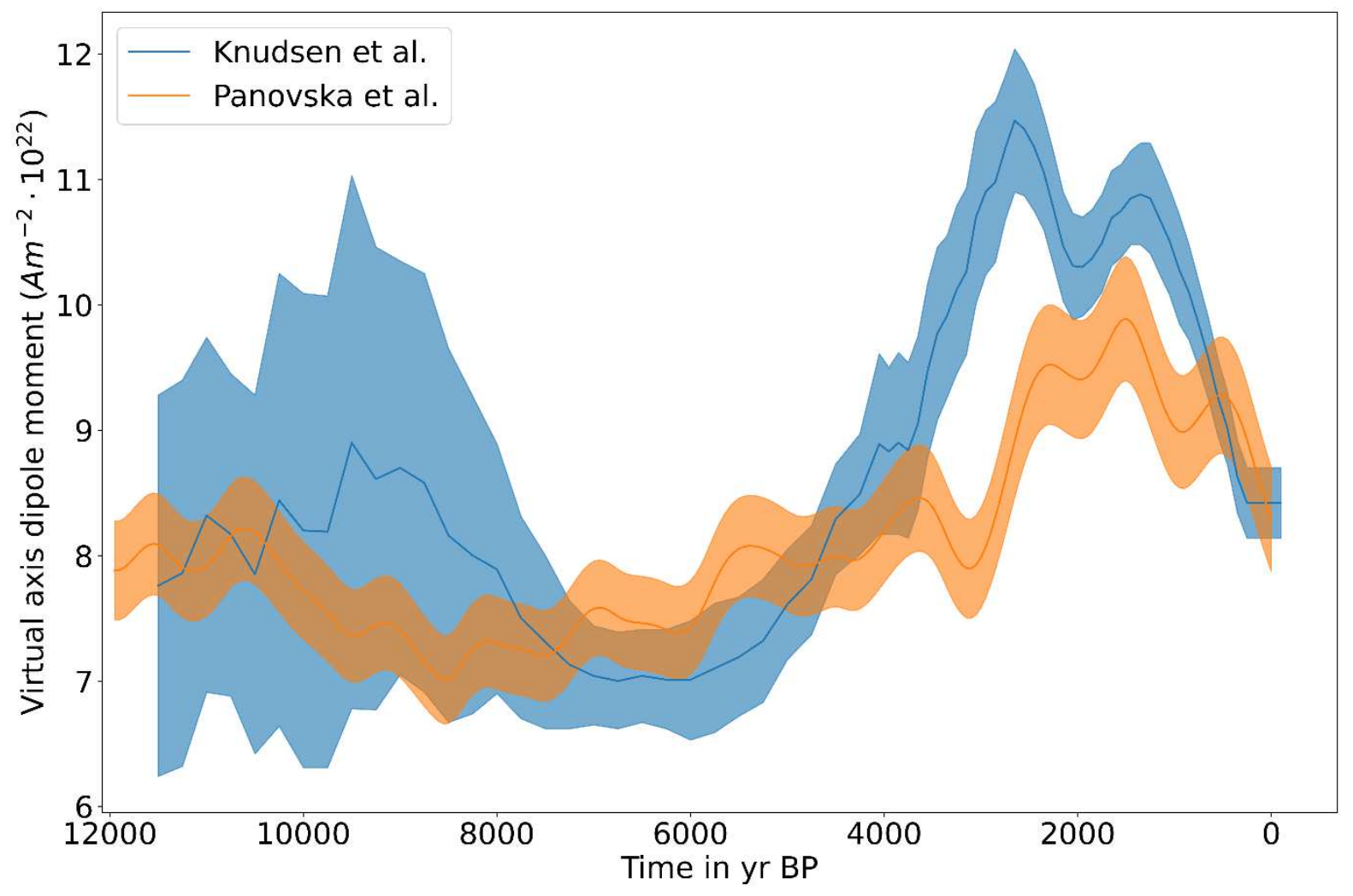

Supplementary Fig. 5 Comparison of two geomagnetic field reconstructions. Two geomagnetic field reconstructions by Knudsen et al. ${ }^{42}$ (blue) and Panovska et al. ${ }^{41}$ (orange) over the last 12000 years including 1- $\sigma$ uncertainty ranges. 


\section{Supplementary Files}

This is a list of supplementary files associated with this preprint. Click to download.

- Fig1sourceData.xIsx

- SupplementaryFig1 sourcedata.xlsx

- SupplementaryFigures.pdf

- Supplements.pdf 